\title{
Unloading Effects of Vasodilators on Peripheral Circulation and Cardiac Hemodynamics in Patients with Acute Myocardial Infarction
}

\author{
Yoshihiko Seino, M.D.,* Teruo Takano, M.D., \\ Takao Endo, M.D., Kanji Obayashi, M.D., \\ Hirokazu Hayakawa, M.D., John K. Vyden, M.B., \\ Harold B. Rose, Sci.D., and Eiichi Kimura, M.D.
}

\section{SummaRY}

Effects of three representative vasodilators on peripheral and cardiac hemodynamics were studied in 20 patients with heart failure due to acute myocardial infarction ( $\mathrm{PCWP}>18 \mathrm{mmHg}, \mathrm{Cl}>2.20$ $\mathrm{L} / \mathrm{min} / \mathrm{m}^{2}$ ) using venous occlusion plethysmography and a SwanGanz catheter. Sublingual isosorbide dinitrate (ISDN) significantly increased calf venous capacitance (CVC) from 5 to $60 \mathrm{~min}$ $(\mathrm{p}<0.01)$ and calf blood flow $(\mathrm{CBF})$ in the initial $15 \mathrm{~min}(\mathrm{p}<0.05)$, while simultaneously lowering PGWP $(\mathrm{p}<0.05)$ and central venous pressure $(\mathrm{p}<0.05)$. Calf vascular resistance $(\mathrm{GVR})$, cardiac index, blood pressure, and total systemic peripheral resistance (TSPR) were not affected significantly. Nitroglycerin ointment (NGO) significantly decreased CVR $(\mathrm{p}<0.05)$ and increased $\mathrm{CVG}(\mathrm{p}<$ 0.05 ) from 60 to $240 \mathrm{~min}$, simultaneously with lowering of PCWP $(p<0.01)$, central venous pressure $(p<0.05)$, and TSPR $(p<0.05)$. Oral prazosin $\left(\mathrm{P}_{\mathrm{z}}\right)$ increased $\mathrm{CBF}(\mathrm{p}<0.01)$ and $\mathrm{CVC}(\mathrm{p}<0.05)$ from 60 to $240 \mathrm{~min}$, simultaneously with significant lowering of PCWP $(\mathrm{p}<0.01)$ and TSPR $(\mathrm{p}<0.05)$, resulting in increased stroke work index $(p<0.05)$. These data confirm that ISDN predominantly causes capacitance vessel dilatation and reduce excessive venous return, while $\mathrm{Pz}$ and NGO dilate not only capacitance vessels but also resistance vessels, consequently reducing systemic vascular re-

From the First Department of Medicine and Section of Coronary Care Unit, Nippon Medical School, Tokyo, Japan, and the Department of Cardiology, Cedars-Sinai Medical Center, School of Medicine, UCLA, Los Angeles, California.

* Recipient of a Grant for research works from the Japan Educational Ministry, Science and Culture, Tokyo, Japan (1980).

* Dr. Seino's present address: Department of Cardiology, Cedars-Sinai Medical Center, School of Medicine, UCLA, Los Angeles, California, USA.

Received for publication November 10, 1981.

Manuscript revised January 12, 1982.

Address for reprint: Yoshihiko Seino, M. D., First Department of Medicine, Nippon Medical School, 1-1-5, Sendagi, Bunkyo-ku, Tokyo 113, Japan. 
sistance and resulting in increased peripheral blood flow and cardiac performance. It was observed that the higher the base-line calf vascular resistance rose, the better the response to the vasodilator treatment appeared in terms of a decrease in calf vascular resistance.

\section{Additional Indexing Words:}

Isosorbide dinitrate Nitroglycerin ointment Prazosin Venous occlusion plethysmography Heart failure

$\mathrm{I}^{\mathrm{N}}$

chronic heart failure both peripheral resistance vessels and capacitance vessels constrict to maintain circulatory homeostasis, i.e., to maintain tissue perfusion and redistribute reduced cardiac output away from peripheral extremities and improve central venous return. ${ }^{1)-5}$ )

While the mechanism of vasoconstriction in acute myocardial infarction may share features in common with those operative in chronic heart failure, ${ }^{61,7)}$ there are also probably important differences, since there is little time to develop and regulate identical compensatory mechanisms because of the sudden onset and rapid aggravation of hemodynamics in acute myocardial infarction. A vicious cycle might be easily provoked in acute myocardial infarction. Thus the compensatory mechanisms might not be entirely beneficial but somewhat overactive in terms of peripheral vascular resistance being higher and cardiac output lower than the most salutary levels. Correspondingly, systemic venoconstriction might also be excessive, thereby resulting in a greater increase of left ventricular filling pressure than is required relative to cardiac output on the flattened ventricular function curve of impaired contractility.

Unloading treatment has been advocated in recent years, since vasodilators possess the ability to interrupt this vicious cycle by partially counteracting compensatory mechanisms. ${ }^{8)}$ To analyze the mechanism of unloading effects of vasodilators, not only cardiac but also peripheral hemodynamics should be measured simultaneously and sequentially. ${ }^{91}$

Accordingly, the present study was carried out to qualify the primary effects of isosorbide dinitrate, nitroglycerin ointment, and prazosin on the peripheral circulation and the resulting cardiac hemodynamic modifications in patients with acute myocardial infarction.

\section{Patients AND Methods}

Twenty patients (13 males, 7 females, mean age 56, range 41-72 years) were studied in the first 72 hours after the onset of acute myocardial infarction 
in the Coronary Care Unit of Nippon Medical School. All patients had acute transmural myocardial infarction complicated by heart failure, confirmed by serial electrocardiographic changes, enzyme determinations and hemodynamic monitoring (PCWP $>18 \mathrm{mmHg}$ ). This study was explained to each patient or his or her family and written informed consent obtained.

Five to $10 \mathrm{mg}$ of isosorbide dinitrate (ISDN) were administered sublingually to 7 patients, $0.5 \mathrm{mg} / \mathrm{Kg}$ BW of nitroglycerin ointment (NGO) were applied to the epigastric area with occlusive dressing technic in 7 patients, and 1 to $2 \mathrm{mg}$ of prazosin were administered orally to 6 patients.

The patients were grouped according to the Killip classification ${ }^{10)}$; in the ISDN group all 7 patients were in class II, in the NGO group 4 were in class II, and 3 were in class III, and in the Pz group 2 were in class II and 4 were in class III. No patients received cardiotonic agents, diuretics or other drugs influencing the peripheral circulation except for oxygenation through a nasal cannula or face mask during the study period.

Peripheral and cardiac hemodynamic measurements were done simultaneously and sequentially. Peripheral hemodynamic measurements were performed at the calf using a pneumatic plethysmograph (EDI, pneumoplethysmograph Winsor "Vasograph") with the patient supine as described previously. ${ }^{11)-14)}$ Venous occlusion technic was used for the measurement of calf blood flow. The plethysmographic cuff was placed around the mid-calf. The second cuff was applied just above the knee which allowed an immediate pressure increase by sudden inflation to $30 \mathrm{mmHg}$. Calf blood flow was calculated from the rate of change in volume during venous occlusion and expressed in unit of $\mathrm{ml} / 100 \mathrm{ml} / \mathrm{min}$. During recording, blood flow to the foot was occluded by the use of the third cuff inflated to a suprasystolic level of pressure (usually $200-250 \mathrm{mmHg}$ ) for at least $1 \mathrm{~min}$ before determination of blood flow. Calf venous capacitance was measured by equilibration method. ${ }^{15}$ The venous occlusion cuff was suddenly inflated to $30 \mathrm{mmHg}$ and then venous pressure and limb circumference were permitted to equilibrate for more than $2 \mathrm{~min}$. Calf venous capacitance was calculated from the increments in volume and expressed in unit of $\mathrm{ml} / 100 \mathrm{ml}$. During measurements, the calf was elevated to the level of heart. Calf vascular resistance was defined as mean arterial pressure measured at the popliteal artery by Korotkoff's method divided by calf blood flow and expressed in unit of $\mathrm{mmHg} / \mathrm{ml} / 100 \mathrm{ml} / \mathrm{min}$. Mean blood pressure (BPm) was calculated by using the formula $\mathrm{BPm}=$ diastolic blood pressure $+1 / 3$ (systolic-diastolic pressure). The room temperature of the Coronary Care Unit was maintained at $24 \pm 1^{\circ} \mathrm{C}$ to prevent effects on the peripheral circulation.

A Swan-Ganz thermodilution catheter was passed from the antecubital 
vein to the pulmonary artery with the aid of electrocardiographic and pressure monitoring. Pulmonary artery pressure, pulmonary capillary wedge pressure (PCWP), obtained by balloon inflation, and central venous pressure were recorded. Cardiac output (CO) was determined by the thermodilution technic using an Edwards' Model 9520A Cardiac Output Computer. Mean blood pressure (BPm) was measured using a \#19 Teflon cannula inserted in a radial or a femoral artery, or by Korotkoff's method at the right brachial artery. In addition, the following cardiac hemodynamic parameters were calculated:

Cardiac index $(\mathrm{CI})=\frac{\mathrm{CO}}{\text { Body Surface Area }}\left(\mathrm{L} / \mathrm{min} / \mathrm{m}^{2}\right)$

Stroke volume index (SVI)

$$
=\frac{\mathrm{CO} \times 1000}{\text { Body Surface Area } \times \text { Heart Rate }}\left(\mathrm{ml} / \mathrm{beat} / \mathrm{m}^{2}\right)
$$

Stroke work index $(\mathrm{SWI})=\mathrm{SVI} \times(\mathrm{BPm}-\mathrm{PCWP}) \times 0.0136\left(\mathrm{Gm} \cdot \mathrm{m} / \mathrm{beat} / \mathrm{m}^{2}\right)$

Total systemic peripheral resistance (TSPR)

$$
=\frac{(\mathrm{BPm}-\mathrm{CVP})}{\mathrm{CI}} \times 79.9\left(\text { dyne } \cdot \mathrm{sec} \cdot \mathrm{cm}^{-5} / \mathrm{m}^{2}\right) \text {. }
$$

All hemodynamic measurements were performed before the administration of each drug as basal control and at 5, 15,30, and 60 min after the sublingual administration of ISDN, at 15, 30, 60, 90, 120, 240 min after applying NGO on the epigastric region, and at 30,60,90,120, 180, $240 \mathrm{~min}$ after the oral administration of $\mathrm{Pz}$.

All data were expressed as the mean \pm standard deviation and statistical

\begin{tabular}{|c|c|c|c|c|c|}
\hline & Before & $5 \mathrm{~min}$ & $15 \mathrm{~min}$ & $30 \mathrm{~min}$ & $60 \mathrm{~min}$ \\
\hline BPm (mmHg) & $100.7 \pm 20.3$ & $98.5 \pm 17.8$ & $92.4 \pm 16.2$ & $93.1 \pm 16.6$ & $94.4 \pm 12.7$ \\
\hline HR (beats/min) & $98.9 \pm 10.2$ & $98.4 \pm 14.6$ & $96.4 \pm 11.8$ & $94.6 \pm 9.2$ & $95.6 \pm 9.2$ \\
\hline PCWP (mmHg) & $24.3 \pm 2.2$ & $17.1 \pm 5.4^{* *}$ & $14.6 \pm 4.5^{* *}$ & $16.2 \pm 4.9 * *$ & $17.1 \pm 6.9$ \\
\hline CVP $\left(\mathrm{cmH}_{2} \mathrm{O}\right)$ & $9.0 \pm 2.8$ & $6.4 \pm 2.7^{*}$ & $5.7 \pm 3.0 *$ & $5.5 \pm 3.5^{*}$ & $5.9 \pm 2.9 *$ \\
\hline $\mathrm{CI}\left(\mathrm{L} / \mathrm{min} / \mathrm{m}^{2}\right)$ & $3.28 \pm 0.16$ & $3.0 \pm 0.4$ & $3.5 \pm 0.4$ & $3.27 \pm 0.28$ & $3.15 \pm 0.16$ \\
\hline SVI $\left(\mathrm{ml} /\right.$ beat $\left./ \mathrm{m}^{2}\right)$ & $33.5 \pm 2.9$ & $31.1 \pm 5.2$ & $33.1 \pm 5.3$ & $34.5 \pm 3.6$ & $33.3 \pm 3.5$ \\
\hline SWI (Gm-m/beat/m²) & $34.6 \pm 8.9$ & $33.4 \pm 8.8$ & $34.3 \pm 5.9$ & $33.6 \pm 5.1$ & $33.5 \pm 4.2$ \\
\hline $\begin{array}{l}\text { TSPR } \\
\left(\text { dyne-sec-cm }-5 / \mathrm{m}^{2}\right)\end{array}$ & $2190.9 \pm 518.9$ & $520.6 \pm 585.3$ & $2205.1 \pm 463.0$ & $2036.8 \pm 445.2$ & $2179.7 \pm 372.2$ \\
\hline CBF $(\mathrm{ml} / 100 \mathrm{ml} / \mathrm{min})$ & $1.19 \pm 0.49$ & $1.83 \pm 0.98 *$ & $1.40 \pm 0.63 *$ & $1.26 \pm 0.57$ & $1.34 \pm 0.75$ \\
\hline CVC $(\mathrm{ml} / 100 \mathrm{ml})$ & $0.42 \pm 0.19$ & $0.61 \pm 0.26^{*}$ & $0.66 \pm 0.24 * *$ & $0.65 \pm 0.21 * *$ & $0.68 \pm 0.24^{\text {** }}$ \\
\hline$\underset{(\mathrm{mmHg} / \mathrm{ml} / 100 \mathrm{ml} / \mathrm{min})}{\operatorname{CVR}}$ & $103.7 \pm 63.9$ & $13.8 \pm 28.5$ & $73.3 \pm 27.8$ & $81.7 \pm 31.8$ & $88.7 \pm 47.4$ \\
\hline
\end{tabular}

Table I. Isosorbide Dinitrate 
analyses were performed using Student's t-test for paired data, comparing each value to its corresponding basal control.

\section{RESUL'TS}

Hemodynamic effects of ISD $\mathcal{N}(n=7)$

For the purpose of analyses, hemodynamic data measured simultane-

\section{ISDN subl.}

$N=7$

\section{Peripheral hemodynamics}
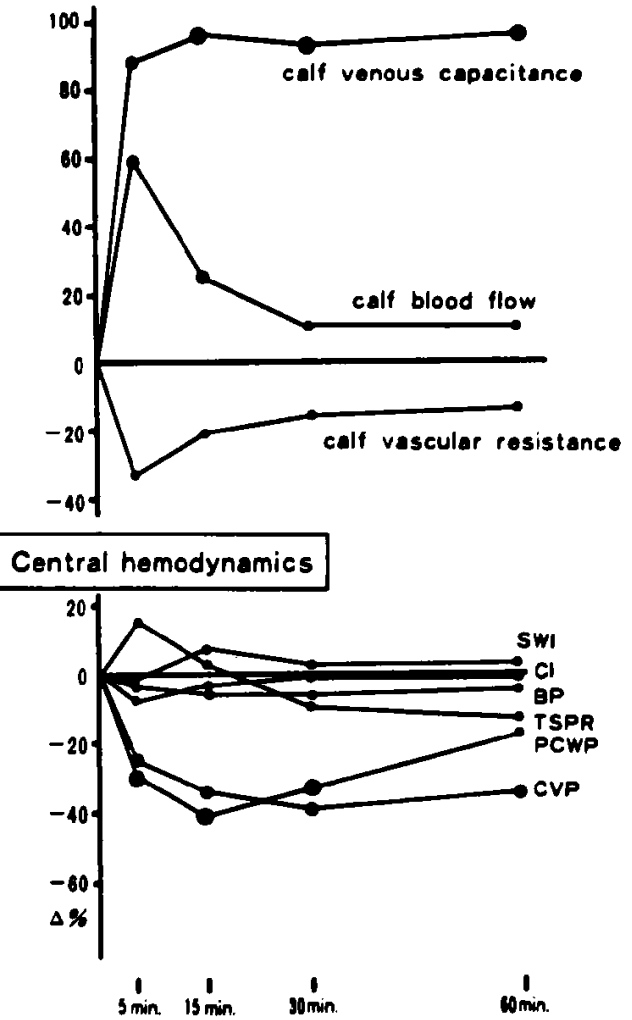

paired tetest

$p<0.05$
$p<0.01$

Fig. 1. Hemodynamic effects of sublingual isosorbide dinitrate (ISDN) on peripheral circulation and cardiac hemodynamics: drafted on percent changes. Calf venous capacitance increased significantly from 5 to $60 \mathrm{~min}$ and calf blood flow increased significantly in the initial 15 min. Corresponding to these peripheral hemodynamic changes, PCWP and CVP decreased significantly from 5 to $30 \mathrm{~min}$ and CVP decreased significantly from 5 to 60 min after the administration. 
ously and sequentially are shown in Table $I$, and the percent changes in Fig. 1 . Calf venous capacitance increased significantly from 5 to $60 \mathrm{~min}(0.42 \pm 0.19$ to $0.68 \pm 0.24 \mathrm{ml} / 100 \mathrm{ml}, \mathrm{p}<0.01$ ) and calf blood flow rose in the initial $15 \mathrm{~min}$ $(1.29 \pm 0.49$ to $1.83 \pm 0,98 \mathrm{ml} / 100 \mathrm{ml} / \mathrm{min}, \mathrm{p}<0.05)$ after the administration. Concomitant with these peripheral hemodynamic changes, PCWP decreased significantly from 5 to $30 \mathrm{~min}(24.3 \pm 2.2$ to $14.6 \pm 4.5 \mathrm{mmHg}, \mathrm{p}<0.01)$ and CVP decreased $\left(9.0 \pm 2.8\right.$ to $\left.5.5 \pm 3.5 \mathrm{~cm} \mathrm{H} \mathrm{H}_{2} \mathrm{O}, \mathrm{p}<0.05\right)$ from 5 to $60 \mathrm{~min}$. Calf vascular resistance, $\mathrm{BPm}, \mathrm{Cl}, \mathrm{HR}, \mathrm{SVI}$, and TSPR were not affected significantly. PCWP showed a tendency of reelevation $60 \mathrm{~min}$ after the administration, indicating that the duration of action of ISDN was short (about 30 to $60 \mathrm{~min}$ ).

Table II. Nitroglycerin

\begin{tabular}{l|c|c|c}
\hline & Before & $15 \mathrm{~min}$ & $30 \mathrm{~min}$ \\
\hline BPm (mmHg) & $102.4 \pm 13.9$ & $95.4 \pm 18.1$ & $95.4 \pm 18.1$ \\
HR (beats/min) & $100.7 \pm 11.2$ & $101.6 \pm 11.6$ & $100.1 \pm 9.1$ \\
PCWP (mmHg) & $28.9 \pm 6.8$ & $24.1 \pm 6.3$ & $16.9 \pm 4.4^{* *}$ \\
CVP (cmH $\mathrm{O}$ ) & $13.4 \pm 6.8$ & $10.3 \pm 6.5^{*}$ & $7.9 \pm 5.8^{* *}$ \\
CI $\left(\mathrm{L} / \mathrm{min} / \mathrm{m}^{2}\right)$ & $2.22 \pm 0.74$ & $2.17 \pm 0.72$ & $2.22 \pm 0.77$ \\
SVI (ml/beat $\left./ \mathrm{m}^{2}\right)$ & $22.5 \pm 8.4$ & $21.9 \pm 9.3$ & $22.6 \pm 9.3$ \\
SWI (Gm-m/beat $\left./ \mathrm{m}^{2}\right)$ & $22.8 \pm 9.3$ & $21.6 \pm 10.2$ & $24.1 \pm 11.2$ \\
TSPR (dyne-sec-cm $\left.-5 / \mathrm{m}^{2}\right)$ & $3573.6 \pm 889.3$ & $3439.5 \pm 779.6$ & $3636.2 \pm 1618.3$ \\
CBF (ml/100 ml/min) & $1.30 \pm 0.76$ & $1.37 \pm 0.78$ & $1.68 \pm 1.23$ \\
CVC (ml/100 ml) & $0.49 \pm 0.22$ & $0.57 \pm 0.20$ & $0.60 \pm 0.21$ \\
CVR (mmHg/ml/100 $\mathrm{ml} / \mathrm{min})$ & $111.7 \pm 72.65$ & $90.48 \pm 36.20$ & $86.10 \pm 57.37 *$
\end{tabular}

Mean \pm standard deviation, paired t-test, ${ }^{*} \mathrm{p}<0.05,{ }^{* *} \mathrm{p}<0.01, \mathrm{~N}=7 . \quad \mathrm{CBF}=$ calf blood flow ;

Table III.

\begin{tabular}{l|c|c|c}
\hline & Before & $30 \mathrm{~min}$ & $60 \mathrm{~min}$ \\
\hline BPm (mmHg) & $112.6 \pm 18.6$ & $102.7 \pm 18.4^{*}$ & $103.2 \pm 21.4$ \\
HR (beats/min) & $90.5 \pm 16.2$ & $99.2 \pm 12.0$ & $94.5 \pm 18.7$ \\
PCWP (mmHg) & $25.3 \pm 2.2$ & $17.7 \pm 4.8^{* *}$ & $16.8 \pm 4.9 * *$ \\
CVP (cmH $\left.{ }_{2} \mathrm{O}\right)$ & $8.4 \pm 4.1$ & $6.4 \pm 3.7$ & $5.7 \pm 3.0$ \\
CI (L/min/m $\left./ \mathrm{m}^{2}\right)$ & $2.36 \pm 0.71$ & $2.36 \pm 0.70$ & $2.58 \pm 0.89$ \\
SVI (ml/beat $\left./ \mathrm{m}^{2}\right)$ & $25.8 \pm 9.1$ & $25.8 \pm 9.3$ & $2.81 \pm 14.8$ \\
SWI (Gm-m/beat $\left./ \mathrm{m}^{2}\right)$ & $31.1 \pm 15.5$ & $32.3 \pm 16.0$ & $36.6 \pm 27.8$ \\
TSPR (dyne-sec-cm $\left.-5 / \mathrm{m}^{2}\right)$ & $4065.2 \pm 1817.6$ & $2426.7 \pm 1124.6^{*}$ & $3427.8 \pm 1370.1$ \\
CBF (ml/100 ml/min) & $0.86 \pm 0.42$ & $0.91 \pm 0.33^{*}$ & $1.16 \pm 0.31^{*}$ \\
CVC (ml/100 ml) & $0.36 \pm 0.13$ & $0.51 \pm 0.13^{*}$ & $0.50 \pm 0.13^{*}$ \\
CVR (mmHg/ml/100 ml/min) & $164.3 \pm 102.9$ & $124.9 \pm 36.1 *$ & $94.2 \pm 36.1^{*}$
\end{tabular}

Mean \pm standard deviation, paired t-test, ${ }^{*} \mathrm{p}<0.05, * * \mathrm{p}<0.01, \mathrm{~N}=7$. CBF $=$ calf blood flow; 
Hemodynamic effects of $\mathcal{N G O}(n=7)$

The peripheral and cardiac hemodynamic changes occurring after NGO application are shown in Table II and Fig. 2. Calf vascular resistance decreased significantly from 30 to $60 \mathrm{~min}(111.70 \pm 72.65$ to $86.10 \pm 57.37 \mathrm{mmHg}$ / $\mathrm{ml} / 100 \mathrm{ml} / \mathrm{min}, \mathrm{p}<0.05$ ) and calf venous capacitance increased significantly from 90 to $120 \mathrm{~min}(0.49 \pm 0.22$ to $0.67 \pm 0.17 \mathrm{ml} / 100 \mathrm{ml}, \mathrm{p}<0.05)$ after the application. Concomitant with these peripheral hemodynamic changes, $\mathrm{BPm}$ (from 60 to $180 \mathrm{~min}$ ) and TSPR (from 120 to $180 \mathrm{~min}$ ) decreased significantly $(p<0.05)$. Significant decreases were also noted in PGWP from 30 to 180 $\min (28.6 \pm 6.8$ to $14.4 \pm 3.2 \mathrm{mmHg}, \mathrm{p}<0.01)$ and in GVP from 150 to 180 $\min \left(13.4 \pm 0.8\right.$ to $\left.6.7 \pm 4.9 \mathrm{~cm} \mathrm{H}_{2} \mathrm{O}, \mathrm{p}<0.05\right)$ after NGO. Calf blood flow,

Ointment

\begin{tabular}{|c|c|c|c|}
\hline $60 \mathrm{~min}$ & $90 \mathrm{~min}$ & $120 \mathrm{~min}$ & $180 \mathrm{~min}$ \\
\hline $90.3 \pm 10.5^{*}$ & $85.2 \pm 7.7^{*}$ & $86.6 \pm 7.9^{*}$ & $85.7 \pm 6.9^{*}$ \\
$98.8 \pm 11.1$ & $96.4 \pm 10.0$ & $96.7 \pm 10.3$ & $94.7 \pm 12.4$ \\
$14.8 \pm 3.2^{* *}$ & $15.2 \pm 3.1^{* *}$ & $15.4 \pm 3.8^{* *}$ & $14.4 \pm 3.2^{* *}$ \\
$6.7 \pm 4.9^{*}$ & $7.1 \pm 4.7^{*}$ & $8.5 \pm 4.3^{*}$ & $9.2 \pm 5.1^{*}$ \\
$2.36 \pm 0.66$ & $2.24 \pm 0.46$ & $2.28 \pm 0.45$ & $2.54 \pm 0.57$ \\
$24.7 \pm 9.0$ & $23.4 \pm 5.7$ & $24.1 \pm 6.7$ & $27.6 \pm 8.9$ \\
$25.1 \pm 9.0$ & $22.8 \pm 7.7$ & $23.9 \pm 7.4$ & $26.7 \pm 8.3$ \\
$3039.4 \pm 795.8$ & $2910.8 \pm 296.4$ & $2892.3 \pm 455.6^{*}$ & $2584.6 \pm 591.7^{*}$ \\
$2.07 \pm 0.84$ & $1.81 \pm 1.77$ & $1.42 \pm 0.83$ & $1.57 \pm 1.02$ \\
$0.62 \pm 0.24$ & $0.67 \pm 0.17^{*}$ & $0.66 \pm 0.20^{*}$ & $0.63 \pm 0.13^{*}$ \\
$86.90 \pm 60.92^{*}$ & $88.7 \pm 58.82$ & $88.94 \pm 54.76$ & $89.91 \pm 64.19$ \\
\hline
\end{tabular}

$\mathbf{C V G}=$ calf venous capacitance $; \mathrm{CVR}=$ calf vascular resistance.

Prazosin

\begin{tabular}{|c|c|c|c|}
\hline $90 \mathrm{~min}$ & $120 \mathrm{~min}$ & $180 \mathrm{~min}$ & $240 \mathrm{~min}$ \\
\hline $101.9 \pm 13.0$ & $102.4 \pm 15.6$ & $101.0 \pm 11.3$ & $102.1 \pm 13.3$ \\
$97.2 \pm 10.7$ & $95.8 \pm 16.1$ & $93.3 \pm 14.6$ & $93.6 \pm 14.4$ \\
$15.0 \pm 4.4^{* *}$ & $15.3 \pm 4.4^{* *}$ & $16.5 \pm 3.8^{* *}$ & $17.1 \pm 3.3^{* *}$ \\
$5.6 \pm 2.9$ & $5.6 \pm 3.6$ & $5.4 \pm 2.9$ & $4.0 \pm 1.6$ \\
$2.77 \pm 0.50$ & $2.64 \pm 0.42$ & $2.66 \pm 0.37$ & $2.71 \pm 0.48$ \\
$29.4 \pm 8.7$ & $29.1 \pm 10.3$ & $30.0 \pm 9.8$ & $30.8 \pm 10.0$ \\
$36.1 \pm 17.0^{*}$ & $36.7 \pm 17.7^{*}$ & $35.4 \pm 17.0$ & $36.2 \pm 15.7$ \\
$2764.4 \pm 422.4$ & $3155.6 \pm 613.2$ & $2955.6 \pm 415.7$ & $2955.2 \pm 524.1$ \\
$1.77 \pm 0.76^{* *}$ & $1.56 \pm 0.44^{*}$ & $1.84 \pm 0.55^{* *}$ & $1.46 \pm 0.34^{*}$ \\
$0.67 \pm 0.27^{*}$ & $0.58 \pm 0.13^{*}$ & $0.56 \pm 0.21 *$ & $0.61 \pm 0.20^{*}$ \\
$103.4 \pm 43.3^{*}$ & $67.9 \pm 24.4^{*}$ & $62.0 \pm 16.8^{*}$ & $75.6 \pm 25.0 *$ \\
\hline
\end{tabular}

$\mathbf{C V G}=$ calf venous capacitance $\mathbf{C V R}=$ calf vascular resistance. 


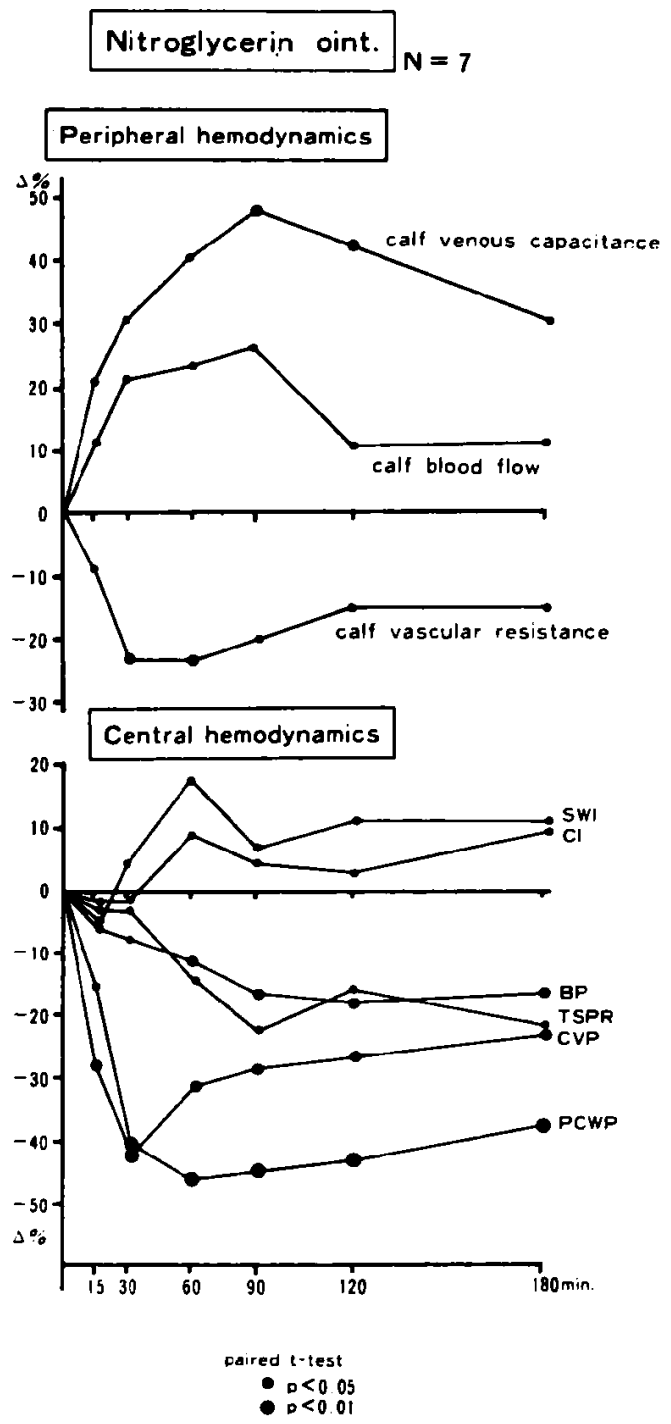

Fig. 2. Hemodynamic effects of nitroglycerin ointment (NGO) on peripheral circulation and cardiac hemodynamics: drafted on percent changes. Calf vascular resistance decreased significantly from 30 to $60 \mathrm{~min}$ and calf venous capacitance increased from 90 to $120 \mathrm{~min}$ after application. Corresponding to these peripheral hemodynamic changes, BP, TSPR, PCWP, and GVP decreased significantly, although CI, SWI, and calf blood flow did not change significantly.

HR, GI, SVI, and SWI were not influenced significantly.

Hemodynamic effects of $P z(n=6)$

Hemodynamic changes after the oral administration of $\mathrm{Pz}$ are shown in Table III and Fig. 3. Galf venous capacitance $(0.36 \pm 0.13$ to $0.67 \pm 0.27 \mathrm{ml} /$ 


\section{Prazosin $]_{N}=6$}

Peripheral hemodynamics

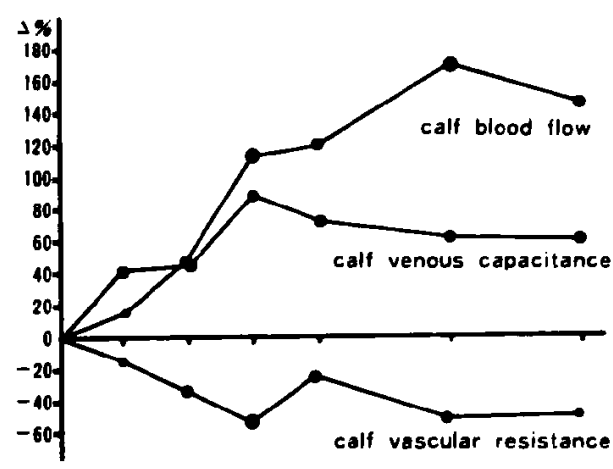

Central hemodynamics

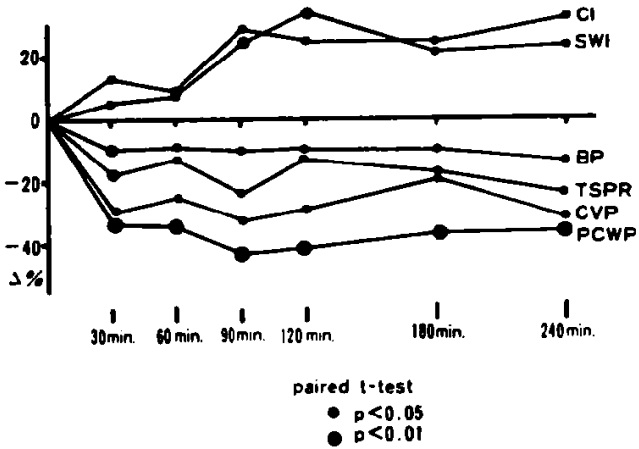

Fig. 3. In patients treated with prazosin $(\mathrm{Pz})$ calf venous capacitance and calf blood flow increased significantly from 30 to $240 \mathrm{~min}$, and calf vascular resistance decreased significantly from 60 to $240 \mathrm{~min}$. Concomitant with these peripheral hemodynamic changes, PCWP was lowered from 30 to 240 $\mathrm{min}$ and SWI increased from 90 to $120 \mathrm{~min}$. CI and SVI showed a tendency to increase, although not significantly.

$100 \mathrm{ml}, \mathrm{p}<0.05)$ and calf blood flow $(0.86 \pm 0.42$ to $1.84 \pm 0.55 \mathrm{ml} / 100 \mathrm{ml} / \mathrm{min}$, $\mathrm{p}<0.05$ ) increased significantly from 30 to $240 \mathrm{~min}$, while calf vascular resistance decreased significantly from 60 to $240 \mathrm{~min}(164.3 \pm 102.9$ to $62.0 \pm 16.8$ $\mathrm{mmHg} / \mathrm{ml} / 100 \mathrm{ml} / \mathrm{min}, \mathrm{p}<0.05)$ after the administration. Concomitant with these significant peripheral hemodynamic changes, PCWP was lowered significantly from 30 to $240 \mathrm{~min}(25.3 \pm 2.2$ to $15.0 \pm 4.4 \mathrm{mmHg}, \mathrm{p}<0.01)$ and SWI increased from 90 to $120 \mathrm{~min}\left(31.1 \pm 5.5\right.$ to $36.7 \pm 17.7 \mathrm{Gm} \cdot \mathrm{m} / \mathrm{beat} / \mathrm{m}^{2}$, $\mathrm{p}<0.05)$. BPm and TSPR decreased significantly $30 \mathrm{~min}$ after the administration. GI and SVI tended to increase and GVP tended to decrease; however 
these changes did not reach levels of statistical significance.

\section{Discussion}

The hemodynamic effects of the three drugs are compared in Table IV.

We demonstrated that ISDN resulted in a decrease in PCWP and CVP associated with an increase in calf venous capacitance, whereas there were no significant changes in cardiac output, BPm, systemic peripheral resistance and calf vascular resistance. As reported previously ${ }^{16)-21)}$ the predominant hemodynamic effect of ISDN was a reduction in preload, resulting from dilation of peripheral capacitance vessels. Our results reconfirmed these effects and additionally demonstrated an initial increase in calf blood flow; this may suggest that ISDN may produce transient arteriolar dilatation. Franciosa et al ${ }^{10), 20)}$ reported similar findings, i.e., an increase in cardiac output, with $40 \mathrm{mg}$ doses of oral ISDN in patients with chronic heart failure. Leier et al ${ }^{18)}$ also reported a mild increase in cardiac output after the administration of $20 \mathrm{mg}$ of ISDN in patients with low cardiac output congestive heart failure. These studies suggested that changes in cardiac output induced by vasodilators would be dependent on base-line hemodynamic status. ${ }^{18)-201}$ In the present study, smaller doses (5-10 mg) of ISDN were administered sublingually in patients with hemodynamic subsets (PCWP $>18 \mathrm{mmHg}, \mathrm{CI}>2.2 \mathrm{~L} / \mathrm{min} /$ $\mathrm{m}^{2}$ ) complicated only by backward failure, ${ }^{22), 23)}$ which might be related to the lack of a further increase in cardiac output.

The present study proved that NGO affected not only capacitance vessels

Table IV.

\begin{tabular}{l|c|c|c}
\hline & $\begin{array}{c}\text { ISDN subl. } \\
(\mathrm{n}=7)\end{array}$ & $\begin{array}{c}\text { NGO } \\
(\mathrm{n}=7)\end{array}$ & $\begin{array}{c}\text { Prazosin } \\
(\mathrm{n}=6)\end{array}$ \\
\hline $\begin{array}{l}\text { Peripheral hemodynamics } \\
\text { Calf blood flow }\end{array}$ & $\uparrow(5-15 \mathrm{~min})$ & $\mathrm{NS}$ & $\uparrow(30-240 \mathrm{~min})$ \\
Galf vascular resistance & $\mathrm{NS}$ & $\downarrow(30-60 \mathrm{~min})$ & $\downarrow(60-180 \mathrm{~min})$ \\
Calf venous capacitance & $\uparrow(5-60 \mathrm{~min})$ & $\uparrow(90-180 \mathrm{~min})$ & $\uparrow(30-240 \mathrm{~min})$ \\
\hline Cardiac hemodynamics & & & \\
Mean BP & NS & $\downarrow(60-180 \mathrm{~min})$ & $\downarrow(30 \mathrm{~min})$ \\
HR & NS & NS & NS \\
PCWP & $\downarrow(5-30 \mathrm{~min})$ & $\downarrow(30-240 \mathrm{~min})$ & $\downarrow(30-240 \mathrm{~min})$ \\
CVP & $\downarrow(5-60 \mathrm{~min})$ & $\downarrow(15-240 \mathrm{~min})$ & $\mathrm{NS}$ \\
CI & NS & NS & NS \\
SVI & NS & NS & NS \\
SWI & NS & NS & $\uparrow(90-120 \mathrm{~min})$ \\
TSPR & & $\downarrow(120-180 \mathrm{~min})$ & $\downarrow(30 \mathrm{~min})$
\end{tabular}


to increase peripheral venous pooling and lower elevated preload, but also resistance vessels to reduce systemic and calf vascular resistance. However, the expected increases in cardiac index or calf blood flow were not proven statistically.

Taylor et al $^{24)}$ examined cardiac and peripheral hemodynamic effects of NGO in congestive heart failure for the first time. They demonstrated a decrease in PCWP and an increase in cardiac output with a concomitant decrease in peripheral vascular resistance and an increase in peripheral venous capacitance. Our results were similar to their report except for lack of the increase in cardiac index. The reason for this discrepancy might be in a difference in the base-line hemodynamic values of cardiac index, i.e., in their study mean cardiac index was lower $\left(1.7 \mathrm{~L} / \mathrm{min} / \mathrm{m}^{2}\right)$ than that in the present study $\left(2.2 \mathrm{~L} / \mathrm{min} / \mathrm{m}^{2}\right)$. Other previous studies ${ }^{25)-27)}$ have also demonstrated a decrease in systemic and forearm vascular resistance in addition to the predominant effect of preload reduction with nitroglycerin.

In contrast to the short duration of action of ISDN, percutaneously absorbed NGO showed a more prolonged influence on hemodynamic parameters and an afterload reduction effect.

Although all three drugs reduced PCWP with a concomitant increase in calf venous capacitance and NGO showed a significant decrease in systemic and calf vascular resistance, only prazosin $(\mathrm{Pz})$ significantly improved stroke work index.

Several studies have been done concerning this point, i.e., the pre- and afterload reduction effects of $\mathrm{Pz}$ in the treatment of heart failure. ${ }^{27-29)}$ Awan et $\mathrm{al}^{28), 30)}$ initially reported the effects of $\mathrm{Pz}$ on cardiac hemodynamics and peripheral circulation in patients with congestive heart failure. They demonstrated that $\mathrm{Pz}$ induced peripheral venodilatation to lower excessive preload, and peripheral arteriolodilatation to augment lowered cardiac output, suggesting potential benefits of $\mathrm{Pz}$ for the relief of pulmonary congestion and the improvement of cardiac performance.

Our results were in agreement with their study except for lack of the increase in cardiac output. This may be due to the difference in base-line cardiac output, i.e., mean cardiac index changed from 1.95 to $2.89 \mathrm{~L} / \mathrm{min} / \mathrm{m}^{2}$ in their study and from 2.36 to $2.77 \mathrm{~L} / \mathrm{min} / \mathrm{m}^{2}$ in the present study.

Lopez-Sendon et $\mathrm{al}^{31)}$ employed $\mathrm{Pz}$ for the treatment of complicated AMI for the first time. They demonstrated that $\mathrm{Pz}$ alleviated pulmonary congestion and improved cardiac output by reducing LV filling pressure and aortic impedance. The present analyses of peripheral hemodynamic effects would corroborate these results. 


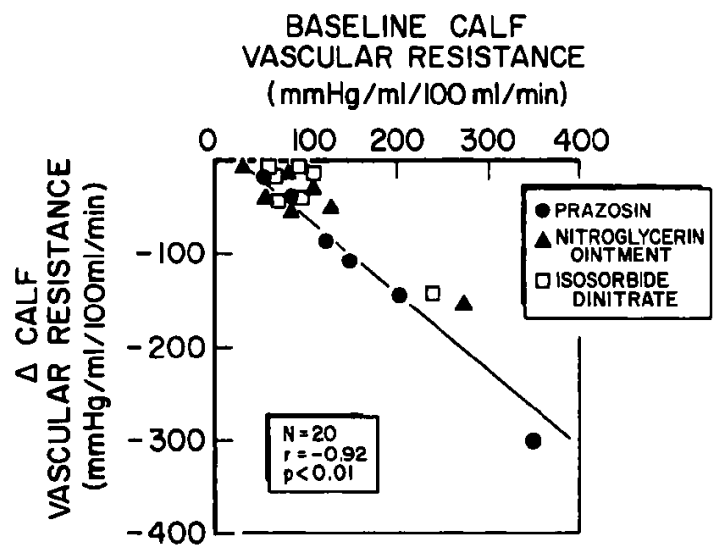

Fig. 4. Correlation between base-line and post treatment calf vascular resistance $(n=20, r=0.92, p<0.01)$. It was found that the higher the baseline calf vascular resistance, the better the effect appeared in terms of decreased calf vascular resistance.

\section{Peripheral hemodynamic changes in relation to base-line hemodynamic values}

As previously reported it is known that changes in cardiac hemodynamics are somewhat dependent on base-line hemodynamic status. ${ }^{18), 20)}$ However, little analysis has been done concerning how the base-line peripheral hemodynamic status is related to the resulting hemodynamic changes. When relationships between base-line and posttreatment peripheral hemodynamic changes were considered (Fig. 4), highly negative correlation was noted for the calf vascular resistance, i.e., $r=-0.99(p<0.01)$ in patients treated with prazosin, $r=-0.87(\mathrm{p}<0.01)$ in NGO treatment, $r=-0.87(\mathrm{p}<0.01)$ in ISDN treatment, and $r=-0.92(\mathrm{p}<0.01)$ in all 20 patients. This means that the higher the base-line calf vascular resistance, the greater was the decrease elicited by vasodilator treatment. However, the base-line calf blood flow or calf venous capacitance values showed no significant correlation to the changes in these parameters following vasodilator administration.

\section{Conclusion}

The present study was done to qualify the primary effects of vasodilator therapy on the peripheral vessels and resultant cardiac hemodynamic modifications in patients with acute myocardial infarction.

ISDN predominantly affected capacitance vessels to increase peripheral venous capacitance and reduce excessive venous return (PCWP and/or GVP), while $\mathrm{Pz}$ and NGO dilated not only capacitance vessels but also resistance vessels, thereby reducing peripheral vascular resistance and consequently in- 
creasing peripheral blood flow and/or SWI. The effects of the latter two drugs lasted more than $240 \mathrm{~min}$ as compared to $60 \mathrm{~min}$ with ISDN.

Considering the relationship between base-line and posttreatment peripheral hemodynamic changes, it was observed that the higher the base-line calf vascular resistance, the better the effect appeared in terms of a decrease in calf vascular resistance.

\section{Acknowledgments}

The authors wish to express their gratitude to the Department of Cardiology, Cedars-Sinai Medical Center (Swan HJC, M. D. and all other staffs) for the continuous exchange of the studies under fellowship, to Patricia Allen for editorial assistance, to Joye Nunn and Lilian Solomon for secretarial assistance, and to Lance Laforteza for graphics.

\section{ReFERENGES}

1. Zelis R, Longhurst J, Capone RJ, Lee G: Peripheral circulatory control mechanisms in congestive heart failure. Am J Cardiol 32: 481, 1973

2. Zelis R, Nellis SH, Longhurst J, Mason DT: Abnormalities in the regional circulation accompanying congestive heart failure. Progr Cardiovasc Dis 18: 181, 1975

3. Mason DT: Congestive Heart Failure, ed by Mason DT, Yorke Medical Books, New York, 1976

4. Zelis R, Mason DT, Braunwald E: A comparison of effects of vasodilators stimuli on peripheral resistance vessels in normal subjects and in patients with congestive heart failure. $J$ Clin Invest 47: 9601968

5. Zellis $R$ : The contribution of local factors to the elevated venous tone of congestive heart failure. J Clin Invest 54: 219, 1974

6. Lee G: Total and peripheral blood flow in acute myocardial infarction. Brit Heart J 19: 117, 1957

7. Hawn JA, Rhyneer GS, Bristow JD: Forcarm blood flow and venous tone in acute myocardial infarction. Circulation 44 (Suppl II): II-175, 1971

8. Mason DT: Symposium perspective, symposium on vasodilator and inotropic therapy of heart failure. Am J Cardiol 65: 101, 1978

9. Miller RR, Vismura LA, Williams PO, Amsterdam EA, Mason DT: Pharmacological mechanisms for left ventricular unloading in clinical congestive heart failure. Circulat Res 39: 127, 1976

10. Killip T, Kimball JT: Treatment of myocardial infarction in a coronary care unit. Am J Cardiol 20: 457, 1967

11. Vyden JK, Nagasawa K, Graettinger W, Marcus HS, Groseth-Dittrich M, Swan HJC: The effects of transfemoral catheterization on blood flow in the extremities. Circulation 50: 741, 1974

12. Vyden JK, Sellers A, Nagasawa K, Takano T, Groseth-Dittrich M, Swan HJC: Peripheral hemodynamics in anephric patients with hypertension. Am Heart J 96: 203, 1978

13. Hyman $\mathrm{C}$, Winsor $\mathrm{T}$ : The application of the segmental plethysmograph to measurement of blood flow through the limb of human beings. Am J Cardiol 5: 667, 1960

14. Seino Y, Akaike H, Takano T, Obayashi K, Hayakawa $H$ : Changes of peripheral circulation in patients with acute myocardial infarction, noninvasive observation by the lower limb venous occlusion plethysmography. Respir Circulat 29: 297, 1981 (English abstract, text in 
Japanese)

15. Mason DT, Braunwald E: The effects of nitroglycerin and amylnitrate on the arteriolar and venous tone in the human forearm. Circulation 32: 755, 1965

16. Zelis R, Mason DT: Isosorbide dinitrate, effects on the vasodilator response to nitroglycerin. JAMA 234: 166, 1975

17. Franciosa JA, Cohn JN: Immediate effects of hydralazine-isosorbide dinitrate combination on exercise capacity and exercise hemodynamics in patients with left ventricular failure. Circulation 59: 1085, 1979

18. Leier GV, Magorien RD, Desch CE, Thompson MJ, Unverferth DV: Hydralazine and isosorbide dinitrate: comparative central and regional hemodynamic effects when administrated alone or in combination. Circulation $63: 102,1981$

19. Franciosa JA, Cohn JN: Hemodynamic responsiveness to short and long-acting vasodilators in left heart failure. Am J Med 65: 126, 1978

20. Franciosa JA, Black RC, Cohn JN: Nitrate effects on cardiac output and left ventricular outflow resistance in chronic congestive heart failure. Am J Med 64: 207, 1978

21. Gomes JAC, Carambas CR, Moran HE, Dhatt MS, Calon AH, Caracta AR, Damato AN: The effects of isosorbide dinitrate on left ventricular size, wall stress and left ventricular function in chronic refractory heart failure. Am J Cardiol 65: 794, 1978

22. Forrester JS, Diamond GA, Swan HJC: Correlative classification of clinical and hemodynamic function after acute myocardial infarction. Am J Cardiol 39: 137, 1977

23. Forrester JS, Diamond GA, Chatterjee MB, Swan HJC: Medical therapy of acute myocardial infarction by application of hemodynamic subsets. New Engl J Med 295: 1356, 1976

24. Taylor WR, Forrester JS, Magnusson P, Takano T, Ghatterjee K, Swan HJC: Hemodynamic effects of nitroglycerin ointment in congestive heart failure. Am J Cardiol 38: 469, 1976

25. Reichek N, Goldstein RE, Redwood DR: Sustained effects of nitroglycerin ointment in patients with angina pectoris. Circulation 50: 348, 1974

26. Awan NA, Miller RR, Maxwell KS, Mason DT: Cardiocirculatory and antianginal actions of nitroglycerin ointment. Ghest 73: 14, 1978

27. Miller RR, Awan NA, Maxwell KS, Mason DT: Sustained reduction of cardiac impedance and preload in congestive heart failure with the antihypertensive vasodilator prazosin. New Engl J Med 297: 303, 1977

28. Awan NA, Miller RR, Miller MP, Specht K, Verz Z, Mason DT: Clinical pharmacology and therapeutic application of prazosin in acute and chronic refractory congestive heart failure, balanced systemic venous and arterial dilation improving pulmonary congestion and cardiac output. Am J Cardiol 65: 146, 1978

29. Awan NA, Miller RR, Demaria AN, Maxwell KS, Neumann A, Mason DT: Efficacy of ambulatory systemic vasodilator therapy with oral prazosin in chronic refractory heart failure. Circulation 56: 346, 1977

30. Awan NA, Miller RR, Maxwell KS, Mason DT: Effects of prazosin on forearm resistance and capacitance vessels. Clin Pharmacol Ther 22: 79, 1977

31. Lopez-Sendon JH, Coma-Canella I, Lombera F, Jadraque LM: Use of oral prazosin hydrochloride in congestive heart failure following acute myocardial infarction. Am Heart $\mathrm{J}$ 98: 495,1979 